\title{
MOTOR ABILITY PROFILE OF JUNIOR AND SENIOR MALE SOUTH AFRICAN TAEKWONDO ATHLETES
}

\author{
Musa Lewis Mathunjwa ${ }^{a^{*}}$, Sam Mugandani ${ }^{a}$, Abidemi Kappo ${ }^{b}$, \\ Svetoslav Ivanov ${ }^{c}$, Trayana Djarova-Daniels ${ }^{\mathrm{b}}$ \\ $a^{*}$ Department of Biokinetics and Sports Science, University of Zululand, \\ KwaDlangezwa, South Africa; ${ }^{b}$ Department of Biochemistry and Microbiology, \\ University of Zululand, KwaDlangezwa, South Africa. 'Bulgarian Union of \\ Physical Culture and Sport; Bulgarian Taekwondo and Judo federation, Bulgaria.
}

\begin{abstract}
Introduction: The purpose of this study was to assess and compare motor abilities in young and adult male South African taekwondo athletes. To date, knowledge of the motor ability demands of this combat sport is in its infancy. Methodology: Participants were junior $(n=25,15.5 \pm 2.6$ years, $163.0 \pm 13.4 \mathrm{~cm}, 53.3 \pm 1 \mathrm{a} 3.4 \mathrm{~kg})$ and senior $(n=20,15.9 \pm 1.20$ years, $166.8 \pm 7.98 \mathrm{~cm}, 73.4 \pm 10.7)$ males from a local taekwondo (WTF) club in South Africa. Flexibility (sit-and reach), abdominal strength and endurance (60-second sit-ups and 2minutes push ups), explosive leg power (vertical jump), agility (t-test), aerobic power $\left(20 \mathrm{~m}\right.$ bleep test) converted to maximum oxygen uptake $\left(\mathrm{VO}_{2 \max }\right)$ were measured. Data were analysed using t-test for independent samples and Z-score individual radar plots statistics for each athlete. Results: There was no significant difference in agility between juniors (10.9 $\pm 0.4 s)$ and seniors (12.6 \pm $1.2 s)(p>0.05)$. The seniors showed significant of $(p<0.05)$ higher values in sit ups (53.1 \pm 6.1 vs $48.9 \pm 13.8)$, push-ups (76.6 \pm 17.1 vs $25.6 \pm 10.6)$, sit \& reach (54.6 \pm 5.8 vs $40.1 \pm 7.5$ repetitions), horizontal jump (2.6 \pm 1.1 vs $1.9 \pm 0.3)$, and $\mathrm{VO}_{2 \max }(52.5 \pm 2.8 \mathrm{vs} 42.2 \pm 6.6)$ than juniors. The results showed that the performance of senior male Taekwondo athletes are higher than the juniors as expected. Conclusions: More extensive research is required to extend the existing knowledge to permit specialized conditioning in juniors to improve their motor ability at the early stage of Taekwondo training, leading to better combat performance.
\end{abstract}

Keywords: Taekwondo athletes, motor ability

\section{Introduction}

Taekwondo (TKD) was officially accepted as an Olympic combat sport since the Sydney Olympics in 2000 (Lin et al., 2006). Successively, TKD has technically advanced into one of the frequently practiced martial arts sport worldwide with about 70 million participants in 180 countries (Fong \& $\mathrm{Ng}, 2011)$. TKD is a dynamic form of unarmed self-defence that incorporates a variety of techniques for the purpose of attack, and can be distinguished from the other martial arts by its focus on kicking techniques that are performed at a high speed (Bridge et al., 2014; Hammami et al., 2013).

TKD is characterized by three main areas in competition: sparring (free fighting), poomsae (forms), destructions (breaking of wood and tiles) which require complex motor and functional skills, tactical excellence and high levels of fitness to excel $(\mathrm{Cu}-$ lar et al., 2013; Melhim, 2001). International TKD athletes are categorised in different weight divisions for both male and female athletes to participate in poomsae and sparring. Poomsae is a structural form of group competition in which the participant simultaneously used both hands and feet displaying various techniques (Haddad et al., 2014). In Kyo- rugi, combat matches are typically performed in three rounds of 2 minutes with 1-min rest period (World Taekwondo Federation, 2015). Points are awarded when kicks and punches make contact on the allowed body area. A winner is determined by scoring more points or by knockout.

There is an insufficient amount of scientific information on anthropometric and energy demand (Kazemi et al., 2009; Ball 2011), physiological profile (Kazemi et al., 2009), mental development (Chiodo et al., 2011 \& Pieter W., Heijmans, 2000) with high technical and tactical proficiency (Bridge et al., 2011; Kazemi et al., 2009) of TKD sport. Additionally, there is few information regarding gender differences in Taekwondo to determine the impact of physical profile between junior male and females (Mathunjwa et al., 2015). Research on South African senior taekwondo athletes in both International Takwondo Federation (ITF) and World Taekwondo Federation (WTF) is scarce. The purpose of this study was to assess and compare motor abilities in senior and junior male taekwondo athletes.

\section{Methodology:}

Participants were junior $(n=25)$ and senior $(n=20)$ 
males from a local taekwondo (WTF) club in South Africa volunteered to participate in this study. Following an explanation of all procedures, risks and benefits, each subject gave his informed consent to participate in the study. The participants were involved in taekwondo training and were members of the South African Taekwondo Federation. Ethical clearance was obtained from the University of Zululand. Data were analysed using $t$-test for independent samples and Z-score individual radar plots statistics for each athlete.

Procedure

The following tests were administered: anthropometric measurements: flexibility (sit-and- reach test), abdominal strength and endurance (60-second sit-ups and 2minutes push ups test), explosive leg power (vertical jump test), agility (t-test), aerobic power ( $20 \mathrm{~m}$ bleep test) converted to maximum oxygen uptake $\left(\mathrm{VO}_{2 \max }\right)$ were measured.

Anthropometric measurements

Body mass of the individuals was measured in kilogram $(\mathrm{kg})$ using a digital scale (Kubota KA - 10150 V, Japan). Stature was measured using a stadiometer (La Fayette Instrument Co. USA) and body mass index was calculated as weight divided by height squared $\left(\mathrm{kg} / \mathrm{m}^{2}\right)$ (Ross and Marfell-Jones, 1991).

Physical tests and physiological performance measurements

The details of these measurements were presented in a previous paper (Mathunjwa et al., 2015). Flexibility $(\mathrm{cm})$ was measured in centimetres by the modified sit-and-reach test using the Lafayette sit and reach box (Model 01285A, La Fayette, USA). The T-test (sec) was used to determine the agility of body trunk without loss of balance including forward, lateral and backward running (Raven, Gett- man, Pollock, and Cooper 1976; Getchell 1985). Leg power was measured by standing broad jump (cm) (Johnson and Nelson 1986). A tape measure was used (Stanley Power Locks, Tokyo, Japan) to measure the distance after jumping forward on a linoleum floor surface. The $20 \mathrm{~min}$ multi stage fitness test (MSFT) was used to measure endurance capacity. This test measured continuous running between two lines 20 meters apart in time to recorded beeps (Gabbett et al., 2009). Muscular strength and endurance were assessed by the one minute sit-ups and two minutes push-up test (repetitions) respectively (Sparling, 1997).

\section{Statistical analysis}

Data were analysed using mean and standard deviations. An ANOVA was computed to determine if differences exist senior and junior athletes. Significance was set at $\mathrm{p}<0.05$. Due to the relatively small sample size, the statistical power of the study was calculated using two statistical power calculators: Alpha error level criterion set at 0.05 or $5 \%$ confidence level and Beta criterion set at 0.80 or $80 \%$ confidence level (Zodplay, 2004). The Z-criterion statistics (Marronna, Martony, \& Yohar, 2006) was applied for preparing computerized individual performance Z-score radar plots (Mathunjwa et al., 2015) and used for comparison.

\section{Results}

The descriptive statistics of the performance variables in senior and junior South African taekwondo athletes are displayed in Table 1 . Senior taekwondo athletes tend to have higher body mass and stature than juniors. No significant difference noted in BMI and sit ups. Statistically, significantly higher $(p<0.001)$ push-ups, Horizontal Jump, sit and reach and $\mathrm{VO}_{2 \max }(\mathrm{p}<0.05)$ were found in senior athletes compared to junior athletes.

Table 1. Physical characteristics of the South African Taekwondo Senior vs Junior athletes (mean \pm SD).

\begin{tabular}{|c|c|c|c|c|}
\hline Parameters & Senior $(n=20)$ & Junior $(n=25)$ & $\Delta$ & $\% \Delta$ \\
\hline Age (years) & $23.5 \pm 2.5$ & $15.5 \pm 2.6$ & 0.3 & 34.0 \\
\hline Weight (kg) & $68.6 \pm 9.0$ & $53.8 \pm 10.7$ & 0.2 & 21.6 \\
\hline Height $(\mathrm{cm})$ & $166.8 \pm 7.9^{*}$ & $163.0 \pm 13.4$ & 0.2 & 2.3 \\
\hline BMI $\left(\mathrm{kg} / \mathrm{m}^{2}\right)$ & $22.9 \pm 2.3$ & $20.9 \pm 1.3$ & 0.1 & 8.7 \\
\hline Sit \& Reach $(\mathrm{cm})$ & $54.2 \pm 5.8^{*}$ & $40.1 \pm 7.9$ & 0.3 & 26.0 \\
\hline Sit ups $60 \mathrm{~s}$ & $53.1 \pm 6.1$ & $48.9 \pm 13.8$ & 0.1 & 7.9 \\
\hline Push-ups 2mins & $76.8 \pm 17.4^{* *}$ & $25.6 \pm 10.5$ & 0.6 & 66.7 \\
\hline Horizontal Jump (m) & $2.3 \pm 0.3^{*}$ & $1.2 \pm 0.1$ & 0.5 & 47.8 \\
\hline $\mathrm{VO}_{2 \max }(\mathrm{ml} / \mathrm{kg} / \mathrm{min})$ & $52.5 \pm 2.8^{\star}$ & $42.2 \pm 6.8$ & 0.2 & 19.6 \\
\hline
\end{tabular}

${ }^{* *} \mathrm{p}<0.001,{ }^{\star} \mathrm{p}<0.05, \Delta$ : change, $\%$ percentage, $\mathrm{cm}$ : centimeters, kg: kilograms 
Z-criterion statistics was used to design Z-score radar plots based on the following physical characteristics (Sit-and- reach, sit-ups, push-ups, horizontal jump, T-test, aerobic power) that are key to the performance in Taekwondo.
The results of the $\mathrm{Z}$-score individual radar plots (in \%) of TKD of one senior athletes of more less the same weight category are presented in Table 2 and figure 1 and 2 .

Table: 2. Individual Z score (in \%) of senior and junior TKD athletes

\begin{tabular}{|l|l|l|l|l|l|}
\hline Z-score & Sit \& Reach $(\mathbf{c m})$ & Sit ups 60 s & Push-ups 2mins & $\begin{array}{l}\text { Horizontal Jump } \\
(\mathbf{m})\end{array}$ & VO $_{\text {2max }}(\mathbf{m l} / \mathbf{k g} / \mathbf{m i n})$ \\
\hline NM Senior & 51 & 49 & 68 & 2.2 & 52.1 \\
\hline MZ Junior & 42 & 47 & 28 & 1.1 & 42 \\
\hline
\end{tabular}

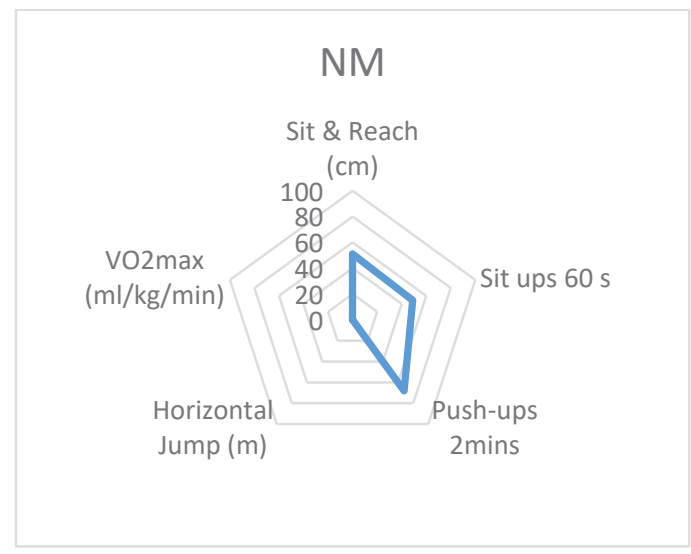

Figure 1: Z-score individual radar plots (in \%) of senior athlete NM

Analysis of Z-score

Athlete N.M. (Figure 1) displayed a higher level of Push ups and good flexibility. His execution will be strong when attacking an opponent. Due to high flexibility, the player will be able to reach the targeted area during his fight. Athlete M.Z. being a junior, has an advantage of his better $\mathrm{VO}_{2 \max } \mathrm{He}$ needs to avoid effective kicks from an opponent by always count attacking so that he can able to last for longer fights since his muscular endurance is poor.

\section{Discussion}

This study has been able to establish the fact that motor ability plays an important role in promoting optimal short and long term health. This is in consonance with (Ortega et al., 2008) while accounting for improved performance. The five main components of motor ability (flexibility, endurance, strength, power and cardiorespiratory fitness) (Ruiz et al., 2006) were assessed in senior and junior athletes. Stature, weight and body mass index (BMI) were also measured at these time points.

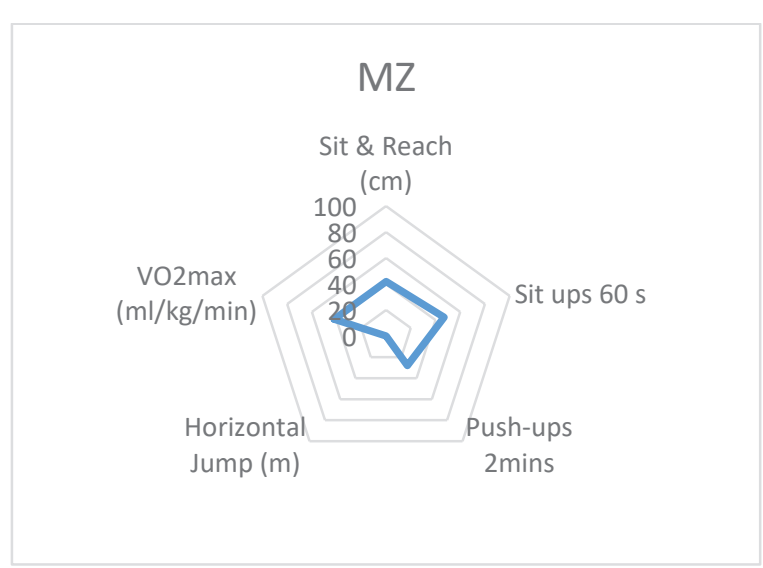

Figure 2: Z-score individual radar plots (in \%) of junior athlete $M Z$

TKD athletes regularly reduce their body mass to compete in selected weight categories and to optimize their power during combat (Tsai et al., 2011). The body mass recorded in this study correlates with data values reported in previous studies and recommended to facilitate performance and maintain good health (Bridge et al., 2014; Rodriguez et al., 2009).

The study also confirms that flexibility plays an important role in TKD and gives athletes an advantage in performing high kicks. As claimed by Chan and colleagues (2001), the authors explained that TKD training enhances flexibility due to the multiple bouts of static and ballistic stretching that increases during physical fitness. It was noted that junior TKD athletes produced lower sit and reach than seniors (see Table 1). Kim et al. (2011) established that training adaptation and the technical demands of sport produce higher flexibility. Therefore, this explains the reason why the senior athletes display higher flexibility scores than the junior (Bridge et al., 2014). 
A study reported that $\mathrm{VO} 2 \mathrm{max}$ scores of junior male TKD athletes ranges between $41-49 \mathrm{ml} / \mathrm{kg} /$ min (Bridge et al., 2011). This shows that the cardiorespiratory fitness of the athletes in our study is comparable with other international athletes (see table 1). Although the value of the senior athletes was higher than the junior nonetheless, the present results met the international standard.

TKD athletes require submaximal muscular endurance and strength to sustain repeated combat movement in competitons (Moir, 2012). The data of sit-ups and push ups in both senior and junior athletes gave an insight of muscular endurance and strength (see Table 1). There are limited studies that examined push ups and sit-ups of international TKD athletes which was in line with our study. (Toskovic et al., 2004; Markovic et al., 2005)

The Z-score radar plots based on the five most relevant motor fitness (flexibility, endurance, strength, power and $\mathrm{VO}_{2 \max }$ ) was measured to assess the individual performance of the TKD athletes. The individual Z-score was implemented in the current study to analyse and interpret the result of the performance in order to provide coaches with information relevant for designing specific training for each athlete.

\section{Reference}

Ball N., Nolan, E. and Wheelere K. (2011). Anthropometrical, physiological, and tracked power profiles of elite taekwondo athletes 9 weeks before the Olympic competition phase. Journal of Strength Conditioning and Resistance 25: 2752-2763.

Bridge, C.A., D.A Silva Santos, J.F., Chaabene, H., Pieter, W. and Franchini, E. (2014). Physical and physiological profiles of taekwondo athletes. Sports Medicine, 44(6): 713-733.

Bridge, C.A., Jones., M.A. and Drust, B. (2011). The activity profile in international taekwondo competition is modulated by weight category. International Journal of Sports Physiology and Performance, 6(3): 344-357.

Chan, S. P., Hong, Y., \& Robinson, P. D. (2001). Flexibility and passive resistance of the hamstrings of young adults using two different static stretching protocols. Scandinavian Journal of Medicine and Science in Sports, $11,81-86$

Chiodo S., Tessitore A., Cortis C., Cibelli G., Lupo C., Ammendolia A., De Rosas M. And Capranica, L. (2011). Stress-related hormonal and psychological changes to official youth taekwondo competitions. Scandinavian Journal Medical Science Sports. 21:111-119.

Chiodo, S., Tessitore, A., Lupo, C., Ammendolia, A., Cortis, C. \& Capranica, L. (2012). Effects of official youth taekwondo competitions on jump and strength performance. European Journal of Sport Science, 12(2), 113-120.

Cular, D., Munivrana, G. and Katić, R. (2013). Anthropological analysis of taekwondo new methodological approach. Collegium Antropologicum, 37(3): 901-906.

Fong, S.S.M. and Ng, G.Y.F. (2011). Does taekwondo training improve physical fitness? Physical Therapy in Sport, 12(2): 100-106.

Gabbett, T., Kelly, J., Ralph, S. and Driscoll, D. (2009). Physiological and anthropometric characteristics of junior eliteand sub-elite rugby league players, with special reference to starters and non-starters. Journal of Science Medicine and Sport, 12(1):215-222.

Haddad, M., Chaouachi, A., Wong Del, P., Castagna, C., Hue, O., Impellizzeri, F.M. \& Chamari, K. (2014). Influence of exercise intensity and during on perceived exertion in adolescent. Taekwondo athletes. European Journal of Sport Science, 14(1): 275-281.

Hammami, N., Zinoubi, B., Hamdi, F., Nouri, A., Zouita, A. and Dziri C. (2013). Isokinetic profile of knee muscles in olympic elite taekwondo practitioners. Science Sports, 28: 188-195.

Johnson, B.I. and Nelson, J.K. (1986). Practical measurements for evaluation in physical education. new york: macmillan publishing company.

Kazemi, M., Casella, C. and Perri, G. (2009). 2004. Olympic taekwondo athlete profile. Journal of the Canadian Chiropractic Association, 53(2): 144-152.

Kim, H., Stebbins, C.L., Chai, J. \& Song, J. (2011). Taekwondo training and fitness in female adolescents. Journal of Sports Sciences, 29 (2), 133-138.

Leger, L.A., Mercier, D., Gadoury, C. and Lambert, J. (1988). The Multistage 20M shuttle run test for aerobic fitness. Journal of Sports Sciences, 6(2): 93-101.

Lin, W.L., Yen K. T., Lu, C.Y.D., Huang, Y.H. and Chang, C.K. (2006). Anaerobic capacity of elite taiwanese taekwondo athletes. Science and Sports, 21 (5): 291-293.

Markovic, G., Misigo-Durakovic, M. \& Trninic S. (2005). Fitness profile of elite Croatian female taekwondo athletes. Collegium Anthropologicum, 29(1), 93-99.

Marronna, R. A., Martony, R.D. \& Yohar, V.J. (2006). Robust Statistics: Theory and Methods: Wiley, New York. Mathunjwa, M.L., Mugandani, S.C., Ngcobo, M., Djarova-Daniels, T. and Ivanov, S. (2015). Physical, anthropometrical, and physiological profiles of experienced junior male and female South African Taekwondo athletes. African Journal for Physical, Health Education, Recreation and Dance, 21(4:2): 1402-1416.

Moir, G. (2012). Muscular endurance. In T. Miller (Ed.), National Strength and Conditioning Association: NSCA's Guide to Tests and Assessments (pp. 193-217). Champaign, IL: Human Kinetics.

Ortega, F. B., Ruiz, J. B., Castillo, M. J., \& Sjo“ stro“m, M. (2008). Physical fitness in childhood and adolescence: A powerful marker of health. International Journal of Obesity,32, 1-11.

Pieter W. and Heijmans J. (2000). Scientific Coaching for Olympic Taekwondo. $2^{\text {nd }}$ ed. Oxford, UK: Meyer \& Meyer Sport. 
Raven, B.P., Gettman, L.R., Pollock, M.L. and Cooper, K.H. (1976). A physiological evaluation of p r of e s sional soccer players. British Journal of Sports Medicine, 10(4): 209-216.

Rodriguez, N.R., DiMarco, N.M. \& Langley, S. (2009). Position of the American Dietetic Association, Dietitians of Canada, and the American College of Sports Medicine: Nutrition and athletic performance. Journal of American Diet Association, 109(3), 509-527.

Ruiz, J. R., Ortega, F. B., Gutierrez, A., Meusel, D., Sjo" stro"m, M., \& Castillo, M. J. (2006). Health-related fitness assessment in childhood and adolescence: A European approach based on the AVEN, EYHA and HELENA studies. Journal of Public Health, 14, 269-277.

Sparling, P.B. (1997). Field testing for abdominal muscular fitness. ACSM's Health Fitness Journal, 1(4): 30-33. Toskovic, N.N., Blessing, D. \& Williford. H.N. (2004). Physiologic profile of recreational male and female novice and experienced Tae Kwon Do practitioners. Journal of Sports Medicine and Physical Fitness, 44(2), 164-172.

Tsai, M.L., Chou, K.M., Chang, C.K. \& Fang, S.H. (2011). Changes of mucosal immunity and antioxidation activ- ity in elite male Taiwanese taekwondo athletes associated with intensive training and rapid weight loss. British Journal of Sports Medicine, 45(9), 729-734.

World Taekwondo Federation [Internet]. World Taekwondo Federation Competition Rules \& Interpretation. [updated 2015] Sep; cited 2015 Dec 3]. Available from http://www.worldtaekwondofederation.net/images/Final_CompetitioRules Amendmen t _E Voting_2015_ copy_copy pdf, 17 .

ZodplaY, S.P. (2004). Sample size and power analysis in medical research. Indian journal of dermatology, venereology and leprology, 70 (2), 123-128, at http://www. dssresearch.com/knowledgecenter/toolkitcalculators/ statisicpowercalculator aspx.

\section{${ }^{\star}$ Corresponding author:}

Musa L Mathunjwa,

Department of Biokinetics and Sports Science, University of Zululand, Private Bag X1001, KwaDlangezwa, 3886

South Africa. Tel: +2735902 6884, Fax: + 27359026386 . Email: mlmathunjwa@gmail.com 